\title{
Groundwater discharges in the Baltic Sea: survey and quantification using a schlieren technique application
}

\author{
V. KARPEN ${ }^{1}$, L. THOMSEN ${ }^{1}$ AND ERWIN SUESS ${ }^{2}$ \\ ${ }^{1}$ International University Bremen, Bremen, Germany; ${ }^{2}$ GEOMAR, Research Center for Marine Geosciences, Kiel, Germany
}

\begin{abstract}
Groundwater seeps are known to occur in Eckernförde Bay, Baltic Sea. Their discharge rate and dispersion were investigated with a new schlieren technique application, which is able to visualize heterogeneous water parcels with density anomalies down to $\Delta \sigma_{\mathrm{t}}=0.049$ on the scale of millimeters. With the use of an inverted funnel, discharged fluids can be captured and the outflow velocity can be determined. Overall, 46 stations could be categorized by three different cases: active vent sites, seep-influenced sites, and non-seep sites. New seep locations were discovered, even at shallow near-shore sites, lacking prominent sediment depression, which indicate submarine springs. The detection of numerous seeps was possible and the groundwater-influenced area was defined to be approximately $6.3 \mathrm{~km}^{2}$. Flow rates of between 0.05 and $0.71 \mathrm{I} \mathrm{m}^{-2} \mathrm{~min}^{-1}$ were measured. A single focused fluid plume, which was not disturbed by the funnel was recorded and revealed a flux of $59.6 \pm 20 \mathrm{ml} \mathrm{cm}^{-2} \mathrm{~min}^{-1}$ and it was calculated that this single focused plume would be strong enough to produce a flow rate through the funnel of $1.32 \pm 0.44 \mathrm{I} \mathrm{m}^{-2} \mathrm{~min}^{-1}$. The effect of different seep-meter funnel sizes is discussed.
\end{abstract}

Keywords: schlieren, Baltic Sea, groundwater, quantification, seepage, submarine springs, visualization

Received 6 July 2005; accepted 20 March 2006

Corresponding author: Volker Karpen, International University Bremen, PO Box 750 561, 28725 Bremen, Germany. Email: v.karpen@iu-bremen.de. Tel: +49 421200 3576. Fax: +49 4212003229.

Geofluids (2006) 6, 241-250

\section{INTRODUCTION}

Knowledge of submarine groundwater discharge is probably as old as seafarers striving to obtain potable water and was first described by Sonrel (1868). Its proportion of the total freshwater flux into the oceans is still unknown and has been underestimated for a long time. During the last two decades the investigation of submarine springs has become a hot topic in marine research. The impact of anthropogenic pollution on the marine environment via the riverine flow is obvious and easy to investigate with common techniques. The release of continental groundwater through artesian aquifers or karst systems is neither visible nor easy to detect. Estimates of the submarine groundwater escape vary enormously. Wide-area flux estimates for the Mid-Atlantic Bight of the US coast are as high as $40 \%$ of the river flow (Moore 1996). The world-wide ratios of direct groundwater discharge to the ocean floor is calculated to be $6 \%$ of the total water influx to oceans and seas (Zektser \& Loaiciga 1993). Thus it appears that for a variety of environmental fields of research such as anthropogenic pollution or the loss of continental groundwaters, the submarine groundwater discharge has to be taken into account (Valiela et al. 1990; Burnett et al. 2001). One of the major challenges is to detect active vent sites and to quantify the fluid flux. For a variety of different seep sites such as cold seeps at active and passive continental margins (Suess et al. 1985; Hovland 1992), different seep-meters have been developed (Lee 1977; Carson et al. 1990; Linke et al. 1994; Tryon et al. 2001). Still, the measurement of flow rates is difficult because they are highly variable over several orders of magnitude (Tryon et al. 2001). This is the reason for the existence of different basic approaches to assess submarine groundwater discharges such as modeling, direct measurements, and tracer techniques (Cable et al. 1996; Turekian et al. 1996; Burnett et al. 2001). Different patterns such as focused or dispersed fluid flux also have to be distinguished and complicate the issue. Hence, not only the measurement of fluid discharges is a frontier, but also the detection of the sources and the tracking of the released fluids. The approach presented in this study was to discover active groundwater seeps, to survey the distribution of dispersed fluids, and to measure the fluid flux. These tasks were performed with an in-situ schlieren technique applica- 
tion (ISTA). The new approach should overcome problems in discovering seepage at shallow water depths within sandy sediments. Furthermore, the application enables tracking of discharge fluids within ambient bottom-water. The study was carried out at Eckernförde Bay, western Baltic Sea.

\section{THE GEOLOGICAL SETTING}

The Baltic Sea was mainly shaped by multiple glaciations during the Pleistocene period. The movement of the continental ice sheet has caused both erosional and depositional features. The post-glacial Eckernförde Bay in its actual form and size was created during the Scandinavian ice sheet retreat after the last glaciation. The shallow bay with an area of $77 \mathrm{~km}^{2}$ has a mean water depth of $20 \mathrm{~m}$ with a prominent till ridge called 'Mittelgrund'.

Eckernförde Bay is one of the most intensely studied shallow water marine environments (Whiticar 2002). The early echo-sounder surveys of Werner (1978) and Whiticar \& Werner (1981) revealed sediment depressions which were termed 'pockmarks' (Edgerton et al. 1966). These elongated, oval depressions are covered by unconsolidated Holocene mud that is easy to penetrate by ascending groundwater (Hovland \& Judd 1988). A system of aquifers with land-sea interaction discharges freshwater via sub-sea floor pathways and is detectable by the low salinity values in pore fluids of sediment samples and bottom-water analysis (Bussmann \& Suess 1998; Bussmann et al. 1999). The source of the freshwater is meteoric water with low salinity charged with more than $600 \mathrm{~mm} \mathrm{yr}^{-1}$ of rainfall (Whiticar 2002). The elevation Mittelgrund seals the older Tertiary sand-aquifer. The younger aquifer consists of a mixture of glacial till and meltwater sediments partly sealed by till and partly by late-glacial glaciolacustrine silt and clay sediments (Schlüter 2001). The upper boundary of the aquifer studied lies only $4 \mathbf{- 5} \mathrm{m}$ below the sea-floor (Sauter et al. 2001). This study area was investigated during the European Union Environment and Climate Research Programme (1994-1998) and its project Sub-GATE (Submarine Groundwater Fluxes and Transport Processes from Methane-Rich Coastal Sedimentary Environment). Different studies were carried out to measure the submarine groundwater flux (Schlüter et al. 2004).

\section{INSTRUMENTATION}

The refractive index of seawater is mainly dominated by salinity and temperature variations (Fig. 1). Light propagates uniformly through homogeneous media, but the transparent medium that was investigated (marine water) is not uniform at all. Disturbances and inhomogeneities due to temperature and salinity variations occur and change the density on a relatively small scale and with it the refractive index. Discharged fluids are always modified compared to

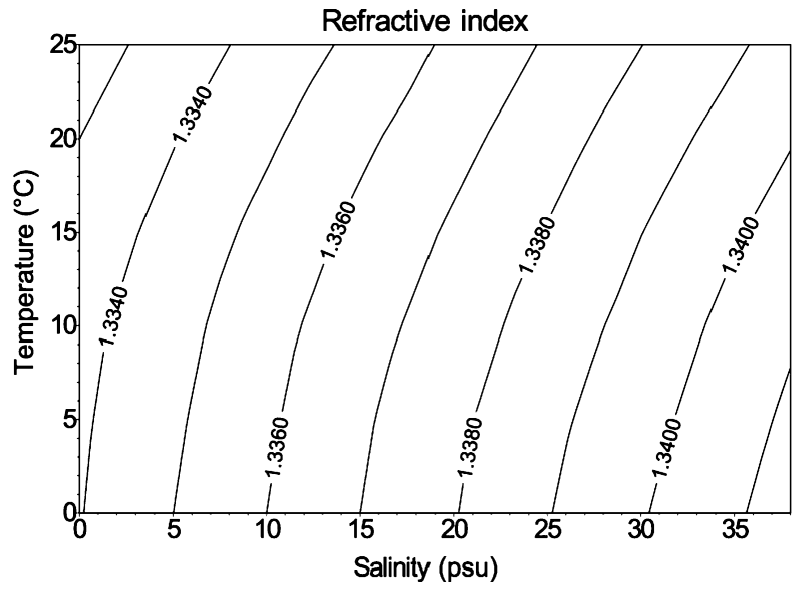

Fig. 1. The refractive index of seawater is mainly dominated by salinity and temperature variations.

seawater because of different chemical and physical properties. For groundwater, the dominant difference relative to the ambient seawater is its distinctively lower salinity, which affects both the density and the refractive index. Submarine groundwater discharges can be visualized with a suitable optical application.

\section{The schlieren technique application}

For this study a former schlieren technique application was improved (Karpen et al. 2004). In contrast to the Z-type ISTA, this new instrument is based on a T-configuration (Schardin 1942; Settles 2001). The term T-configuration is given because of the geometrical arrangement of the components (Fig. 2). The mirror is located opposite to the light source and at a right-angle to the camera. Even though the Z-type mirror system is preferred for most laboratory applications, the T-pattern has crucial advantages for our work. There is only one optical layer instead of three and thus fewer unwanted deviations of the light rays enhance the sharpness of the recordings distinctly. The system is sensitive to small refractive index anomalies

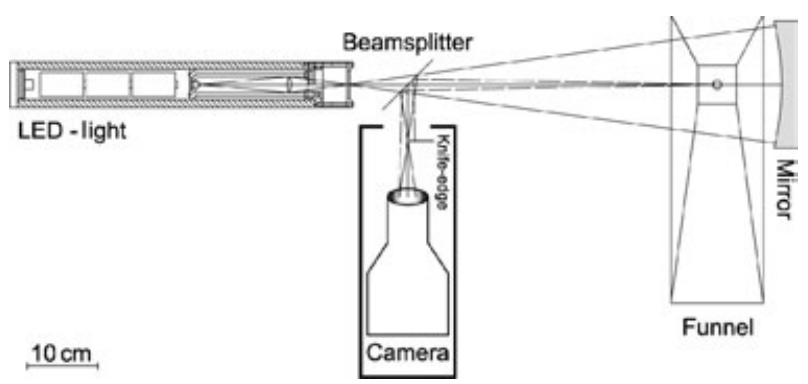

Fig. 2. Schlieren application (top view) with light source, inverted funnel, spherical mirror, beam splitter, and camera. Light rays deflected (dashed lines) from a discharged fluid are visible as schlieren in the video record. 
Table 1 ISTA components, T-type.

\begin{tabular}{ll}
\hline Component & Specification \\
\hline Mirror & Edmund Scientific, spherical, $\varnothing=152.4 \mathrm{~mm}$, \\
& $f=304.8 \mathrm{~mm}, \gamma / 2$ \\
Beamsplitter & $50 \%, 100 \times 100 \times 3 \mathrm{~mm}$ \\
Camcorder & Yashica KX-V1 Hi 8 \\
Camera housing & Aanderaa, O.D. $=129 \mathrm{~mm}$, I.D. $=115 \mathrm{~mm}, 600$ bar \\
LED & $\varnothing=5 \mathrm{~mm}, 20 \mathrm{~mA}$ \\
Power supply & Three A size batteries \\
Lens & $35 \mathrm{~mm}$ \\
Light housing & O.D. $=60 \mathrm{~mm}$, I.D. $=40 \mathrm{~mm}, 600 \mathrm{bar}$ \\
Funnel & Bottom $120 \times 375 \mathrm{~mm}$, top $\varnothing=10 \mathrm{~mm}$ \\
Timer & VCR-Timer for Sony, Yashica camcorder \\
\hline
\end{tabular}

caused by temperature and salinity variations. As already determined (Karpen et al. 2004), density anomalies of at least $\Delta \sigma_{\mathrm{t}}=0.049$ are detectable.

As a light source we used an LED-diode (Table 1). Within the pressure housing, the emitted light is collimated by a $35 \mathrm{~mm}$ lens and refocused on a first knifeedge located at the front. The diverging beam fills the spherical mirror and returns along the coincident path, forming a source image upon the light source itself. By using a beam splitter the returning rays are deflected into the pressure housing of the CCD-Camera. A second knife-edge is located at the focal point right in front of the camera. Approximately $50 \%$ of deflected rays are filtered by the knife-edges. Discharged fluids cause deflection of light rays and they become visible as schlieren on the video recordings. Ideally, each point in the test plane is traversed twice by the same ray, which acquires a deflection angle once on each pass. The sensitivity of the system can be modified by the adjustment of the two blades.

The test area is located directly in front of the mirror. The inverted funnel is integrated in the optical system to capture the ascending fluids. The base area of the funnel is below the frame so it slightly penetrates into the sediment during the bottom time of the deployment. An area of $450 \mathrm{~cm}^{2}$ is covered and the $1 \mathrm{~cm}$ diameter small outlet tube is visible only at the bottom of the video recording. Captured fluids are released through the exhaust port and the jet is visualized. The sediment area in front of the funnel is not covered by the instrument and fluid plumes ascending here are undisturbed and also visible. The field of view is located at $12 \mathrm{~cm}$ height above bottom (h.a.b.).

\section{Flux measurement}

The discharged fluid was captured within the funnel and escaped through the smaller exhaust port. Through video analysis only the smallest detectable particles $(0.1-1 \mathrm{~mm})$ from the center of the jet were tracked to determine the maximum velocity $\left(u_{\max }\right)$ of the discharged jet.

The fluid flow through the funnel was laminar, which was proven by the determination of the Reynolds number. High flow speed values of the calibration experiment as well as of the field experiments do not exceed $2 \mathrm{~cm} \mathrm{~s}^{-1}$ and using this velocity the Reynolds number was calculated, by

$R e=\frac{\rho \bar{u} D}{\mu}=\frac{1000 \times 0.02 \times 0.01}{0.001} \cdot \frac{\mathrm{kg}}{\mathrm{m}^{3}} \cdot \frac{\mathrm{m}}{\mathrm{s}} \cdot \frac{\mathrm{m}}{\mathrm{l}} \cdot \frac{\mathrm{ms}}{\mathrm{kg}}=200$

with the fluids density $(\rho)$, the average velocity $(\bar{u})$, the tube diameter $(D)$, and the coefficient of dynamic molecular viscosity $(\mu)$. A value of $\operatorname{Re} \approx 2000$ represents the transition from laminar to turbulent flow (Massel 1999). The calculated number was 200, which indicates laminar flow conditions.

The velocity distribution of a laminar fluid flow through a pipe has a parabolic shape. The flow through the pipe was identified to be laminar and thus Hagen Poiseuille's law is valid. From this law, it is deduced that the average velocity is half the maximum velocity $\bar{u}=u_{\max } \times 0.5$.

With the known mean velocity $(\bar{u})$, the diameter of the outlet tube and the bottom area of the funnel, the flow rate $(Q)$ per area was calculated by:

$Q=\bar{u} \times \frac{\text { exhaust port area }}{\text { base area }}$

\section{Calibration}

Before the quantification was performed the optical analysis procedure was verified with laboratory calibration and the outlet tube was integrated into the GEOMAR seawater flume (Springer et al. 1999). The spherical mirror was arranged at one side of the flume whereby the light source and the camera were located at the opposite site of the water basin. External water was conducted through a small sediment layer directly through the outlet tube. A known volume of $200 \mathrm{ml}$ was channeled through this experimental design. The fluid flow through the outlet tube was recorded and the discharge rate was determined by using the optical analysis procedure. The elapsed time was measured and the flow rate was calculated. For the first experiment, $200 \mathrm{ml}$ of water was conducted in 5:24 min through the system, which gives a flow rate of $37.08 \mathrm{ml} \mathrm{min}^{-1}$. A repeat experiment achieved a rate of $42.11 \mathrm{ml} \mathrm{min}{ }^{-1}$. For all following flow rates an error of $1 \sigma$ standard deviation is given. The mean value of experiment (a) was $\bar{Q}=34.34 \pm 2.93 \mathrm{ml} \mathrm{min}^{-1}$. For the second run of experiment (b) a mean flow rate of $\bar{Q}=39.79 \pm 4.73 \mathrm{ml} \mathrm{min}^{-1}$ was determined. The results match the true values within the $1 \sigma$ error. The fact that 
they are lower could point to a small systematical error due to the settling velocity of the particles.

\section{THE SURVEY OF SEEPS AND CLASSIFICATION OF STATIONS}

The instrument was repeatedly deployed by the ships of the Leibniz Institute of Marine Sciences (IFM-GEOMAR), Kiel, Germany (RV Littorina, RV Alkor, RV Polarfuchs), and the Federal Armed Forces Underwater Acoustics and Marine Geophysics Research Institute, Kiel, Germany (RV Mittelgrund).

The instrument was deployed as a free-fall system with the use of a buoy for the recovery whereby any disturbances by the ship during the measurement were avoided. According to the sample sites of Bussmann \& Suess (1998), Sauter et al. (2001), and Whiticar (2002), the stations for ISTA were chosen around known pockmark locations. These depressions were made visible with the ships' echo-sounder systems. Additionally, the groundwater aquifer was followed in order to identify new seep locations, to map the distribution of discharged fluids, and to quantify the fluid flux. Therefore, a simplified procedure was defined to characterize each station. Because of the analysis of the video recordings it was possible to distinguish the following categories:

1. Active seep sites

2. Seep-influenced sites; detection of heterogeneous water parcels

3. Non-seep sites; homogeneous bottom-water

All stations with their characteristic venting activity are shown in Fig. 3 and were distinguished with different symbols. The main working area was chosen between the known pockmark location at $54^{\circ} 30^{\prime} \mathrm{N}, 10^{\circ} 02^{\prime} \mathrm{E}$ near Mittelgrund ridge and the pockmark at $54^{\circ} 29^{\prime} \mathrm{N}, 10^{\circ} 01^{\prime} \mathrm{E}$ close to the shore line, to enhance the knowledge of seep-influ- enced areas. Time of deployment, position, and activity are summarized in Table 2. Some of the active seep locations were investigated more than once as indicated by the symbols.

Active vent sites were identified by the fluid discharge within the optical pathway. This could be either a free and undisturbed flow beneath the funnel or a discharge captured by the inverted funnel. The image in Fig. 4A represents an example of a plume which is undisturbed by the instrument and the funnel, ascending directly from the sediment surface (Station 25). The corresponding video sequence shows a continuous discharge of ascending persistently lower density fluids. This very unique fluid flow pattern was observed at only one station and it is easy to see that there was no fluid captured within the funnel simultaneously. This observation is important because it reveals that this plume is very localized at an area scale of centimeters. This station was located at a water depth of $23 \mathrm{~m}$ at close proximity to a pockmark.

In the second image (Fig. 4B), the fluid is focused by the funnel and the jet is visible on the video screen (Station 29). Regularly resuspended particles are visible within this jet. The fastest ones are expelled in the middle of the jet with a velocity of $1-1.8 \mathrm{~cm} \mathrm{~s}^{-1}$.

At some stations a direct fluid discharge through the funnel was also observed but with an outflow pattern that was not as well developed as seen in Fig. 4B. At Station 33 (Fig. 4C), a weak flow discharge is visible. The flux through the sediment is not sufficient to produce a fully developed jet through the exhaust port of the funnel. The slim fluid flow adheres at the walls of the outlet tube due to the surface tension and its diameter is reduced approximately to one half of the exhaust port width. Within this small jet particles are not exactly traceable for a flux measurement and only the ascending schlieren structures were

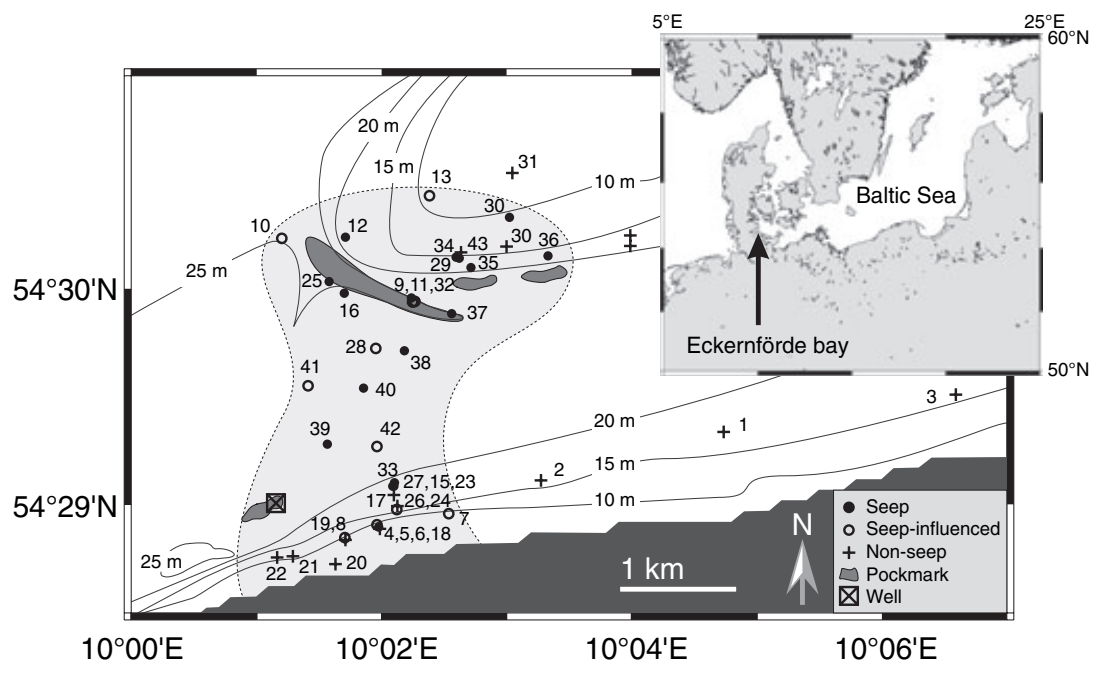

Fig. 3. Map of Eckernförde Bay, Baltic Sea. Stations were chosen mainly between the known pockmarks as well as at shallow areas. The different categories of activity are illustrated with different symbols. The solid dots symbolize an active seep location with a direct fluid discharge through the inverted funnel. The occurrence of heterogeneous water parcels without outflow through the funnel is symbolized by circles. The shaded area of $6.3 \mathrm{~km}^{2}$ encloses all seep-influenced stations. 
Table 2 Stations, Eckernförde Bay. Locations sampled multiple times are labeled by specific symbols in brackets. Same symbols indicate same station with same coordinates.

\begin{tabular}{|c|c|c|c|c|c|c|}
\hline Station No. & UTC & Research vessel & Lat. ('N) & Long. ('E) & Depth (m) & Classification \\
\hline 1 & $16.03 .00,12: 00$ & Littorina & $54^{\circ} 29.343$ & $10^{\circ} 04.736$ & 18 & Non-seep \\
\hline 2 & $16.03 .00,13: 00$ & Littorina & $54^{\circ} 29.116$ & $10^{\circ} 03.277$ & 12 & Non-seep \\
\hline 3 & $16.03 .00,13: 00$ & Littorina & $54^{\circ} 29.517$ & $10^{\circ} 06.596$ & 13.3 & Non-seep \\
\hline $4(\diamond)$ & $04.04 .00,14: 00$ & Littorina & $54^{\circ} 28.904$ & $10^{\circ} 01.969$ & 6.7 & Seep-influenced \\
\hline $5(\diamond)$ & $12.04 .00,11: 00$ & Littorina & $54^{\circ} 28.900$ & $10^{\circ} 01.979$ & 6.7 & Seep-influenced \\
\hline $6(\bullet)$ & $12.04 .00,12: 00$ & Littorina & $54^{\circ} 28.900$ & $10^{\circ} 01.979$ & 6.7 & Seep \\
\hline 7 & $10.05 .00,09: 42$ & Littorina & $54^{\circ} 28.961$ & $10^{\circ} 02.539$ & 10.8 & Seep-influenced \\
\hline $8(\mathrm{C})$ & $10.05 .00,10: 46$ & Littorina & $54^{\circ} 28.850$ & $10^{\circ} 01.709$ & 10.3 & Seep-influenced \\
\hline $9(\mathbf{0})$ & $10.05 .00,11: 14$ & Littorina & $54^{\circ} 29.948$ & $10^{\circ} 02.248$ & 25.8 & Seep-influenced \\
\hline 10 & $10.05 .00,11: 38$ & Littorina & $54^{\circ} 30.243$ & $10^{\circ} 01.203$ & 24.7 & Seep-influenced \\
\hline $11(0)$ & $10.05 .00,12: 00$ & Littorina & $54^{\circ} 29.952$ & $10^{\circ} 02.270$ & 26 & Seep-influenced, muddy \\
\hline 12 & $10.05 .00,12: 36$ & Littorina & $54^{\circ} 30.251$ & $10^{\circ} 01.712$ & 18.6 & Seep \\
\hline 13 & $10.05 .00,13: 04$ & Littorina & $54^{\circ} 30.443$ & $10^{\circ} 02.387$ & 7.9 & Seep-influenced \\
\hline 14 & $10.05 .00,14: 20$ & Littorina & $54^{\circ} 25.632$ & $10^{\circ} 12.011$ & 8 & Non-seep, Kiel Fjord \\
\hline $15\left(^{*}\right)$ & 19.04.01, 15:00 & Mittelgrund & $54^{\circ} 29.089$ & $10^{\circ} 02.091$ & 22 & Seep \\
\hline 16 & 19.04.01, 16:00 & Mittelgrund & $54^{\circ} 29.990$ & $10^{\circ} 01.702$ & 21 & Seep \\
\hline 17 & 19.04.01, 17:00 & Mittelgrund & $54^{\circ} 29.050$ & $10^{\circ} 02.100$ & 15 & Non-seep \\
\hline $18(\bullet)$ & 24.04.01, 10:00 & Polarfuchs & $54^{\circ} 28.890$ & $10^{\circ} 01.990$ & 10 & Non-seep \\
\hline $19(\mathrm{C})$ & $24.04 .01,11: 00$ & Polarfuchs & $54^{\circ} 28.840$ & $10^{\circ} 01.715$ & 7 & Non-seep \\
\hline 20 & $24.04 .01,12: 00$ & Polarfuchs & $54^{\circ} 28.728$ & $10^{\circ} 01.634$ & 5 & Non-seep \\
\hline 21 & $24.04 .01,12: 50$ & Polarfuchs & $54^{\circ} 28.764$ & $10^{\circ} 01.293$ & 10 & Non-seep \\
\hline 22 & $24.04 .01,13: 30$ & Polarfuchs & $54^{\circ} 28.759$ & $10^{\circ} 01.165$ & 4 & Non-seep \\
\hline $23\left(^{*}\right)$ & $24.04 .01,14: 30$ & Polarfuchs & $54^{\circ} 29.089$ & $10^{\circ} 02.091$ & 23 & Seep, muddy \\
\hline $24(\Delta)$ & 07.05.01, 10:00 & Alkor & $54^{\circ} 28.980$ & $10^{\circ} 02.125$ & 20 & Seep-influenced \\
\hline 25 & $07.05 .01,12: 20$ & Alkor & $54^{\circ} 30.042$ & $10^{\circ} 01.580$ & 23 & Plume, quantified \\
\hline $26(\Delta)$ & $07.05 .01,13: 50$ & Alkor & $54^{\circ} 28.997$ & $10^{\circ} 02.129$ & 20 & Non-seep \\
\hline $27\left({ }^{*}\right)$ & 05.06.01, 09:50 & Littorina & $54^{\circ} 29.089$ & $10^{\circ} 02.101$ & 20 & Seep \\
\hline 28 & 05.06.01, 11:00 & Littorina & $54^{\circ} 29.732$ & $10^{\circ} 01.955$ & 23 & Seep-influenced \\
\hline $29(\times)$ & 05.06.01, 11:45 & Littorina & $54^{\circ} 30.152$ & $10^{\circ} 02.624$ & 17.5 & Seep, quantified \\
\hline 30 & $05.06 .01,12: 35$ & Littorina & $54^{\circ} 30.343$ & $10^{\circ} 03.024$ & 10 & Seep, quantified \\
\hline 31 & 05.06.01, 13:30 & Littorina & $54^{\circ} 30.547$ & $10^{\circ} 03.047$ & 7.5 & Non-seep \\
\hline $32(\bullet)$ & 05.06.01, 13:57 & Littorina & $54^{\circ} 29.967$ & $10^{\circ} 02.239$ & 25 & Seep, muddy \\
\hline $33(*)$ & $26.06 .01,09: 50$ & Littorina & $54^{\circ} 29.105$ & $10^{\circ} 02.103$ & 22.1 & Seep, quantified \\
\hline $34(x)$ & $26.06 .01,12: 43$ & Littorina & $54^{\circ} 30.158$ & $10^{\circ} 02.601$ & 17.3 & Seep, muddy \\
\hline 35 & 05.09.01, 10:00 & Littorina & $54^{\circ} 30.108$ & $10^{\circ} 02.718$ & 19.5 & Seep, quantified \\
\hline 36 & 05.09.01, 11:05 & Littorina & $54^{\circ} 30.163$ & $10^{\circ} 03.332$ & 16 & Seep, quantified \\
\hline 37 & 05.09.01, 11:50 & Littorina & $54^{\circ} 29.894$ & $10^{\circ} 02.562$ & 23 & Seep, muddy \\
\hline 38 & $05.09 .01,12: 54$ & Littorina & $54^{\circ} 29.719$ & $10^{\circ} 02.182$ & 23.5 & Seep, muddy \\
\hline 39 & $06.09 .01,10: 25$ & Littorina & $54^{\circ} 29.285$ & $10^{\circ} 01.570$ & 24 & Seep, muddy \\
\hline 40 & 06.09.01, 11:10 & Littorina & $54^{\circ} 29.547$ & $10^{\circ} 01.859$ & 23.5 & Seep, muddy \\
\hline 41 & 06.09.01, 11:53 & Littorina & $54^{\circ} 29.557$ & $10^{\circ} 01.416$ & 23 & Seep-influenced, muddy \\
\hline 42 & 06.09.01, 13:39 & Littorina & $54^{\circ} 29.275$ & $10^{\circ} 01.966$ & 23 & Seep-influenced, muddy \\
\hline 43 & $20.09 .01,09: 46$ & Littorina & $54^{\circ} 30.180$ & $10^{\circ} 02.636$ & 16 & Non-seep \\
\hline 44 & $20.09 .01,10: 50$ & Littorina & $54^{\circ} 30.206$ & $10^{\circ} 03.001$ & 15 & Non-seep \\
\hline 45 & 20.09.01, 11:45 & Littorina & $54^{\circ} 30.209$ & $10^{\circ} 03.991$ & 14 & Non-seep \\
\hline 46 & $20.09 .01,12: 56$ & Littorina & $54^{\circ} 30.257$ & $10^{\circ} 03.991$ & 14 & Non-seep \\
\hline
\end{tabular}

used for a rough quantification. However, this weak seep station reveals the minimum flux which can be analyzed with this application.

Station 16 (Fig. 4D) was located right at a pockmark site. The high resuspension is easily seen as is the strong fluid discharge through the funnel. An adequate quantification of the station was not possible because the fluid/sediment suspension was not transparent enough for an optical analysis even though a vigorous flux becomes visible in the images.
Seep influenced stations were characterized by a heterogeneous water parcel, whereas no fluid flow through the funnel was measurable (Fig. 4E). This phenomenon predicts a close vicinity to an active seep site.

\section{FLUID FLOW QUANTIFICATION}

Particles and distinct schlieren pattern were used for quantification. In some cases it was only possible to use schlieren structures instead of particles due to reduced 

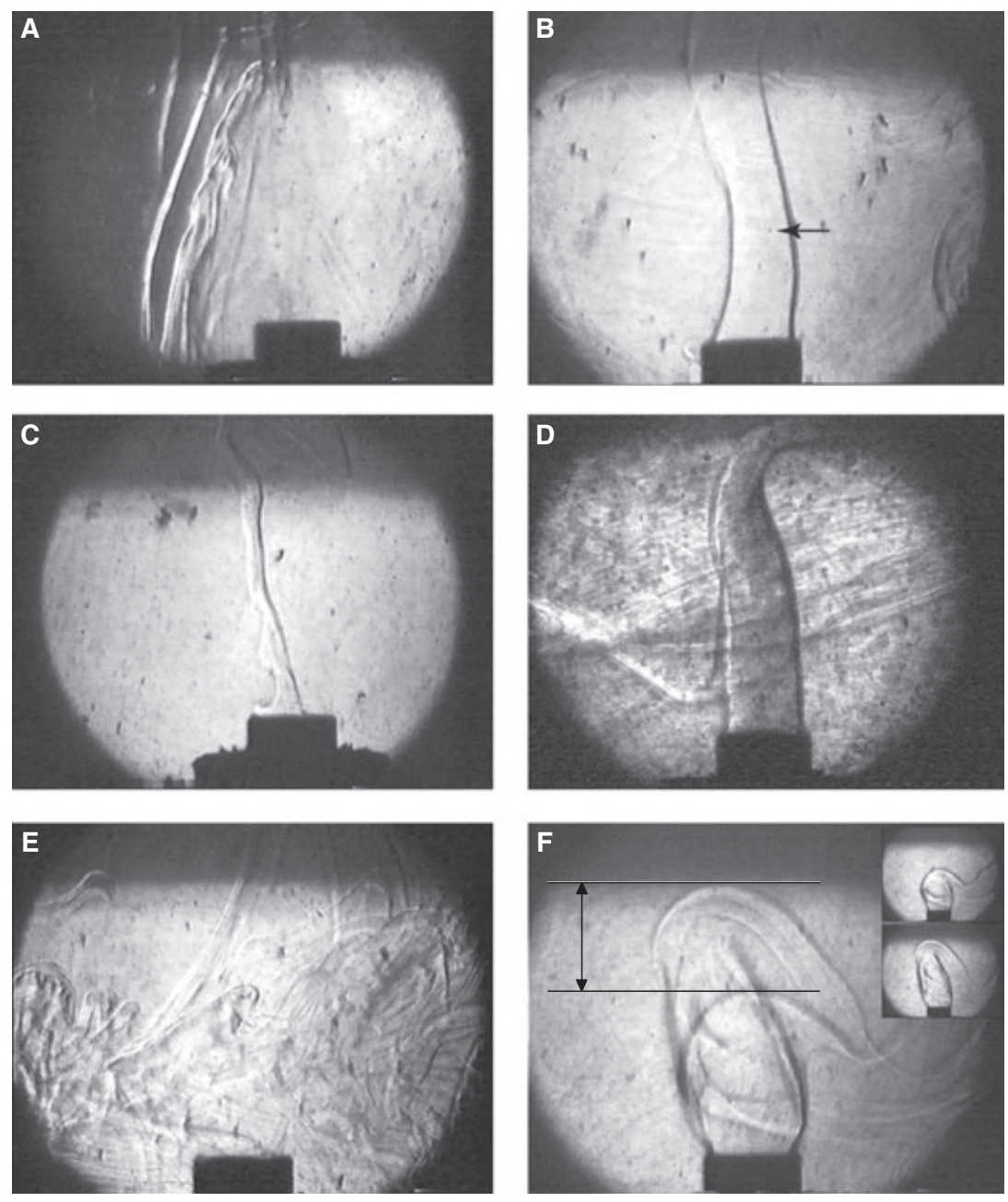

Fig. 4. ISTA-screen-shots from different stations. (A) Station 25: an undisturbed fluid plume, whic$h$ is continuously discharged from the sediment surface. There is no flow through the funnel indicating a very spatially restricted source. The velocity of ascending plumes is determined and is used to calculate the flow rate through the sediment. (B) Station 29: the discharged fluid is captured by the inverted funnel. Resuspended particles are transported within the fluid, marked by an arrow. (C) Station 33: A very weak fluid flow is visible in the image, with a small fluid discharge rate. (D) Station 16: strong fluid discharge at a pockmark site with high particle resuspension. The captured fluid is visibly discharged through the exhaust port. Fluid escape through the sediment is also identified by the very heterogeneous bottom-water surrounding the funnel. (E) Station 28: a seep-influenced site. The bottom-water is very heterogeneous and there is no obvious discharge through the funnel. Discharged fluid due to seepage from areas adjacent to the instrument is transported within the bottom layer. (F) Station 29: Overlay of the two sub images. Ascending fluid plumes are evaluated by tracking the upper schlieren front. The front moves over a known distance which is symbolized by the arrow between the lines. The funnel (12 cm h.a.b.) in all images acts as scale, outer diameter of the outlet nozzle $=12 \mathrm{~mm}$. transparency or the lack of particles. The dynamics of the fluid jet often produced horizons or fronts which ascended and could be tracked (Fig. 4F). The movement and the ascending velocity of these structures were analyzed with the use of image processing software. The jet was tracked over a distance, symbolized by two lines. The flux underestimates the real value because the outer regions of the jet are reduced in velocity. Both methods were exemplary compared for Station 29 at $17.5 \mathrm{~m}$ water depth. Resuspended particles of Station 29 that were used for the quantification are shown in Fig. 4B. The outflow velocities did not exceed $2 \mathrm{~cm}$ (Table 3 ) and thus a laminar flow existed.

The first three rows of Table 3 are based on data obtained by measurements of rising schlieren fronts whereas the others are estimated based on movements of particles. The determined flow rates are plotted in Fig. 5A. A mean flow rate at Station 29 at $17.5 \mathrm{~m}$ water depth of $\bar{Q}=0.71 \pm 0.191 \mathrm{~m}^{-2} \mathrm{~min}^{-1}$ was calculated.

The described instrument covers one section of the sea-floor with the funnel but also monitors one uncovered region. Fluids escaping from the uncovered region
Table 3 Flow velocity and rate (Station 29). Schliere or particle defines how the determination was performed.

\begin{tabular}{llll}
\hline $\begin{array}{l}\text { Flow velocity } \\
\left(u_{\max }\right) \text { through }\end{array}$ & $\begin{array}{l}\text { Flow velocity } \\
\text { through sediment } \\
\text { tube }\left(\mathrm{cm} \mathrm{s}^{-1}\right)\end{array}$ & $\begin{array}{l}\text { Flow rate } \\
\left(1 \mathrm{~m}^{-2} \mathrm{~min}^{-1}\right)\end{array}$ & $\begin{array}{l}\text { Schliere/ } \\
\text { particle }\end{array}$ \\
\hline 0.74 & 0.64 & 0.39 & Schliere \\
0.62 & 0.54 & 0.32 & Schliere \\
0.92 & 0.81 & 0.48 & Schliere \\
1.15 & 1.01 & 0.6 & Particle \\
1.85 & 1.61 & 0.97 & Particle \\
1.03 & 0.89 & 0.54 & Particle \\
1.68 & 1.46 & 0.88 & Particle \\
1.68 & 1.46 & 0.88 & Particle \\
1.32 & 1.15 & 0.69 & Particle \\
1.32 & 1.15 & 0.69 & Particle \\
1.54 & 1.34 & 0.81 & Particle \\
1.68 & 1.46 & 0.88 & Particle \\
1.68 & 1.46 & 0.88 & Particle \\
1.54 & 1.34 & 0.81 & Particle \\
1.03 & 0.89 & 0.54 & Particle \\
1.54 & 1.34 & 0.81 & Particle \\
1.23 & 1.07 & 0.64 & Particle \\
1.68 & 1.46 & 0.88 & Particle \\
1.54 & 1.34 & 0.81 & Particle \\
\hline & & &
\end{tabular}


Table 4 List of determined discharge rates of five stations.

\begin{tabular}{lll}
\hline Station & Flow rate $\left(\mathrm{m}^{-2} \mathrm{~min}^{-1}\right)$ & Tracer \\
\hline 29 & $0.71 \pm 0.19$ & Particles and schlieren \\
30 & $0.61 \pm 0.22$ & Particles and schlieren \\
36 & $0.50 \pm 0.04$ & Particles \\
35 & $0.65 \pm 0.22$ & Particles \\
33 & $0.05 \pm 0.008$ & Schlieren \\
\hline
\end{tabular}

ascended undisturbed from the instrument but were still visible.

At Station 25, water depth of $23 \mathrm{~m}$, a free and undisturbed plume was observed beside the funnel with a diameter of $0.1-0.5 \mathrm{~cm}$ (Fig. $4 \mathrm{~A}$ ). For this special case the quantification procedure was modified. A quantification through the funnel was not possible, but the ascending velocity of the plume was measurable. The outflow velocity of approximately $1 \mathrm{~cm} \mathrm{~s}^{-1}$ was achieved by tracking schlieren structures and was used to estimate a flow rate in milliliter per square centimeter per minute. Based on the shape of the thin filament a mean flow rate of $\bar{Q}=59.6 \pm$ $20 \mathrm{ml} \mathrm{cm}^{-2} \mathrm{~min}^{-1}$ was calculated (Fig. 5D).

\section{DISCUSSION}

Active seep sites were identified by a significant fluid discharge through the funnel. Two active seep sites were discovered at the southern near-shore area with water depths of less than $20 \mathrm{~m}$ (Stations 6, 15/23/27/33). Another five sites were identified as active seeps at the shallow elevation Mittelgrund with comparable water depths (Stations
$12,30,35,36,29 / 34)$. Some recordings of fluid escape were reduced in contrast. An explanation for this phenomenon is an assumed long distance to the groundwater aquifer. Station 30 is located on Mittelgrund ridge and identified as the most northerly seep site at only $10 \mathrm{~m}$ water depth. The enhanced mixing between groundwater and seawater within the sediment could explain the small differences of the refractive index and the reduced contrast.

The known pockmarks are located in water depths of more than $20 \mathrm{~m}$ and are separated in a northern area close to Mittelgrund and a southern area near the shoreline. Three seep sites were recorded between the known pockmarks in the North and the South (Stations 38, 39, 40). The presented fluid discharge records revealed that the aquifer system also releases fluids in this $1.5 \mathrm{~km}$ long transition between the pockmarks, even though no obvious seabed disturbances occur and no fluid venting had been observed before.

Pockmark sites were rarely explored because it is very difficult to obtain samples or recordings even though the highest flow rates are expected there. The strong and persistent fluid discharge supersaturates the pore space of the sediment (Orsi et al. 1996; Nittrouer et al. 1998). The seabed is better described by a fluid/sediment suspension with no clearly defined sediment-water interface. Because of this problem, no video recording was obtained in some cases, and presumably the instrument simply disappeared in the mud. Nevertheless, recordings in some cases were carried out successfully.

The area enclosing both seep sites and seep-influenced sites is determined to be $6.3 \mathrm{~km}^{2}$ (Fig. 3). It was shown
Fig. 5. Selected flux results for variable flow conditions. Flow rate versus time at Stations 29 (Fig. 4B,F) (A). The flow rates were determined by tracking resuspended particles $(X)$, and schlieren fronts $(\otimes)$, respectively. (B) Stations 36 with moderate flow conditions. The flow rate was determined by tracking resuspended particles. (C) The results of a calm flow through the funnel Station 33 (Fig. 4C). The flow rate was determined by tracking specific schlieren structures. (D) Flow rate of an undisturbed fluid discharge at Station 25 (Fig. 4A). There was no flow through the funnel. The ascending velocity of the visible plume was determined and a flow rate calculated.
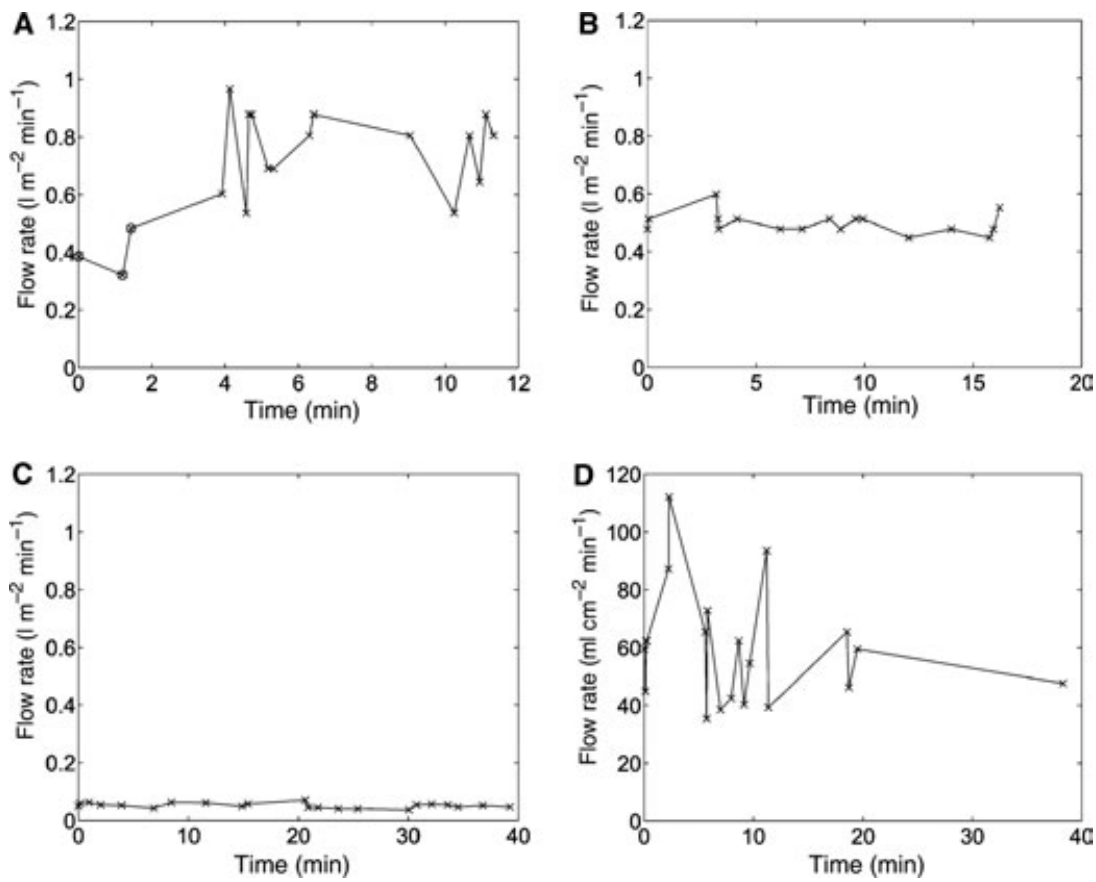
that the venting is not restricted to some discrete pockmark locations. In general two different seep types were distinguished: dispersive fluid discharge, captured with the inverted funnel and focused fluid escape through the sediment-water interface. The second case was only observed at one station. The free flow at Station 25 displayed in Fig. 4A represents a unique flow pattern. The continuous discrete fluid flow with a velocity of approximately $1 \mathrm{~cm} \mathrm{~s}^{-1}$ ascends beside the funnel and hence is undisturbed by the instrument. Because of the bottom-current the outflow direction varies sometimes, but never ended during the time of observation $(40 \mathrm{~min})$. A mean flow rate of $59.6 \pm 20 \mathrm{ml} \mathrm{cm}^{-2} \mathrm{~min}^{-1}$ was determined based on the outflow velocity. Even though this calculation is rough one must take into account that all other barrel-type seepmeters have to cope with backpressure and flow deflection (Tryon et al. 2001). The following calculations can be performed to compare this undisturbed fluid flux through the sediment with the quantifications through the funnel:

$59.6 \pm 20 \frac{\mathrm{ml}}{\operatorname{min~} \mathrm{cm}^{2}} \times \frac{10000}{1000 \times 450}=1.32 \pm 0.44 \frac{1}{\mathrm{~min} \mathrm{~m}^{2}}$

This flux is high as a potentially captured dispersive discharge of $1.32 \pm 0.441 \mathrm{~m}^{-2} \mathrm{~min}^{-1}$ through the funnel (base area $450 \mathrm{~cm}^{2}$ ) and exceeds the measured rates varying from 0.05 to $0.711^{-2} \mathrm{~min}^{-1}$ (Table 4 ). In the described station there is no venting through the funnel and without the visual information this site would be wrongly characterized as a non-seep site. This plume of less dense groundwater displays how naturally focused fluid discharge on the scale of centimeters occurs. Observations supporting these results were taken by divers, who documented structures like small cracks or fissures suggesting local fluid vents (Khandriche \& Werner 1995).

Some of the active or seep-influenced sites were investigated more than once. As displayed in Table 2, a location close to a pockmark site (Stations 9/11/32) was seepinfluenced and active over a time span of a year, which reflects the stable activity of this seep. In general the fluid discharge is steady over a time frame from weeks to years. The recovery of active seepage allows the estimation of a minimum seep size. Based on the ships positioning and deployment variance, a minimum seep site of $1 \mathrm{~m}^{2}$ can be assumed.

For five stations the mean flow rate was determined to be $0.5 \pm 0.271 \mathrm{~m}^{-2} \mathrm{~min}^{-1}$ and varied between 0.05 and $0.711 \mathrm{~m}^{-2} \mathrm{~min}^{-1}$ (Table 4 ).

A quantification for all active seep sites was not possible because of nontransparent water parcels with high sediment load or bottom-currents with velocities more than $2 \mathrm{~cm} \mathrm{~s}^{-1}$. In total, 20 stations were defined as active seep sites and an estimate for the area influenced by groundwater could be accomplished with the mean flow rate of
$0.5 \pm 0.27 \mathrm{l} \mathrm{m}^{-2} \mathrm{~min}^{-1}$ for every single station. A minimum seep size of $1 \mathrm{~m}^{2}$ is assumed because of multiple discharge observations on different deployments at the same locations. Based on 20 known stations (Fig. 3), approximately $14400 \pm 77761 \mathrm{day}^{-1}$ are discharged daily in the groundwater seep-influenced area of $6.3 \mathrm{~km}^{2}$ :

$0.5 \pm 0.27 \frac{1}{\operatorname{min~} \mathrm{m}^{2}} \times 20 \mathrm{~m}^{2} \times 1440=14400 \pm 7776 \frac{\mathrm{l}}{\mathrm{d}}$

This influenced area represents $8.2 \%$ of Eckernförde Bay $\left(77 \mathrm{~km}^{2}\right)$. This result presumably underestimates the total discharge of this area because of the small assumed seep size and the limited amount of discovered seep sites. A drilled well into the aquifer discharges approximately $180001 \mathrm{~m}^{-2} \mathrm{day}^{-1}$ (Suess \& Linke 2001). It has to be considered that the flow through a well is not comparable to natural seeps because the well directly taps the aquifer.

The flow rates presented here could be compared with the VESP-lander measurements, which represents a semienclosed benthic chamber with a large opening at the bottom and a small exhaust port at the top (Linke et al. 1994). Discharge rates of the same working area varying between 20 and $260 \mathrm{l} \mathrm{m}^{-2}$ day $^{-1}$ are reported with highest groundwater fluxes in a pockmark site of $4701 \mathrm{~m}^{-2}$ day $^{-1}$ (Bussmann \& Suess 1998; Suess \& Linke 2001). The outcome of the mean flow rate in this study of $0.5 \pm 0.271 \mathrm{~m}^{-2} \mathrm{~min}^{-1}$ corresponds to $720 \mathrm{l} \mathrm{m}^{-2} \mathrm{day}^{-1}$. These results are still within the same order of magnitude albeit the obtained rate of this study is almost twice as high as the VESP-lander rate. It has to be taken into account that the funnel of the VESP-lander covers an area of $10000 \mathrm{~cm}^{2}$ in contrast to an area of $450 \mathrm{~cm}^{2}$ for the funnel used in this study. If a single focused vent is covered by an inverted funnel, the measured outflow rate decreases with increasing size of the funnel. Hence, different flow meters with different bottom areas will measure different outflow rates. The use of multiple funnels with different sizes within one instrument is required to solve this problem.

\section{CONCLUSIONS}

The detection and quantification of fluid discharge is crucial to understand the biogeochemical processes within the marine environment. Under the current conditions in Eckernförde Bay the escaping fluid does not ascend directly but is captured in the turbulent bottom layer. This is an important process for the distribution of nutrients and organic particles. Implications of seeps to the ecology of the environment are known for instance from methane seeps (Dando et al. 1991; Sibuet \& Olu 1998). Especially the discharge of freshwater is able to decrease the abundance and diversity of benthic communities (Dando 2001). 
Low salinity causes osmotic stress to the marine fauna (Bussmann et al. 1999). Nutrients and other chemical compounds are significantly modified. The freshwater flushing is able to deplete methane concentrations in the sediment close to or below detection levels (Whiticar 2002). The influence of a groundwater seep is measurable in sediment cores (Bussmann et al. 1999; Sauter et al. 2001; Whiticar 2002), but only as long as the station is directly influenced by the seepage.

Active seep sites were not only observed at the pockmark locations but also at adjacent areas where no seepage had been observed so far. Whiticar \& Werner (1981) described that the groundwater movement to the pockmarks can be explained by the geological setting. The till cover at the pockmark locations overlaying the aquifer is thinner and the freshwater breaks through the recent marine sediments (Whiticar 2002). Khandriche \& Werner (1995) observed a close relation between freshwater and the pockmark depressions, which are formed by erosion of the upper layers. In this study further seepage locations were discovered at the shallow elevation Mittelgrund as well as in shallow near-shore areas.

\section{ACKNOWLEDGEMENT}

We gratefully acknowledge Adriano Mazzini and one unknown reviewer for their very detailed and constructive reviews. We greatly appreciate the support at sea by the officers and crews of RV Littorina, RV Alkor, RV Polarfuchs, and RV Mittelgrund and Asmus Petersen technical support. We want to acknowledge Gregor Rehder for his helpful comments to this manuscript. This study was funded by the Deutsche Forschungsgemeinschaft, the graduate school 'Dynamics of Global Cycles' (GRK-171) at the Christian-Albrechts-Universität of Kiel, and the Land Schleswig-Holstein.

\section{REFERENCES}

Burnett WC, Taniguchi M, Oberdorfer J (2001) Measurement and significance of the direct discharge of groundwater into the coastal zone. Journal of Sea Research, 46, 109-16.

Bussmann I, Suess E (1998) Groundwater seepage in Eckernförde Bay (Western Baltic Sea): effect on methane and salinity distribution of the water column. Continental Shelf Research, 18(1415), 1795-806.

Bussmann I, Dando PR, Niven SJ, Suess E (1999) Groundwater seepage in the marine environment: role for mass flux and bacterial activity. Marine Ecology Progress Series, 178, 169-77.

Cable JE, Burnett WC, Chanton JP, Weatherly GL (1996) Estimating groundwater discharge into the northeastern Gulf of Mexico using radon-222. Earth and Planetary Science Letters, 144, 591-604.

Carson B, Suess E, Strasser JC (1990) Fluid flow and mass flux determinations at vent sites on the Cascadia Margin accretionary prism. Journal of Geophysical Research, 95(B6), 8891-7.
Dando P (2001) Biology and biogeochemistry of methane-rich sediments. Sub-G.A.T.E. Environment and Climate Research Programme Task, 6, 1-6.

Dando PR, Austen MC, Burke RA Jr, Kendall MA, Kennicutt MC II, Judd AG, Moore DC, O'Hara SCM, Schmaljohann R, Southward AJ (1991) Ecology of a North Sea pockmark with an active methane seep. Marine Ecology Progress Series, 70, 49-63.

Edgerton H, Seibold E, Vollbrecht K, Werner F (1966) Morphologische Untersuchungen am Mittelgrund (Eckernförder Bucht, westliche Ostesee). Meyniana, 16, 37-50.

Hovland M (1992) Hydrocarbon seeps in northern marine waters - their occurrence and effects. Palaios, 7, 376-82.

Hovland M, Judd AG (1988) Seabed Pockmarks and Seepages: Impact on Geology, Biology and the Marine Environment. Graham \& Trotman, London.

Karpen V, Suess E, Thomsen L (2004) A new 'schlieren' technique application for fluid flow visualization at cold seep sites. Marine Geology, 204(1-2), 145-59.

Khandriche A, Werner F (1995) Freshwater induced pockmarks in Bay of Eckernfoerde, Western Baltic. Proceedings of the Third Marine Geological Conference "The Baltic", Prace Panstwowego Instytutu Geologicznego pp. 155-64.

Lee DR (1977) A device for measuring seepage flux in lakes and estuaries. Limnology and Oceanography, 22, 140-7.

Linke P, Suess E, Torres M, Martens V, Rugh WD, Ziebis W, Kulm LD (1994) In situ measurement of fluid flow from cold seeps at active continental margins. Deep-Sea Research I, 4l(4), 721-39.

Massel SR (1999) Fluid Mechanics for Marine Ecologists. SpringerVerlag, Heidelberg, New York.

Moore WS (1996) Large groundwater inputs to coastal waters revealed by ${ }^{226} \mathrm{Ra}$ enrichments. Nature, 380, 612-4.

Nittrouer CA, Lopez GR, Wright LD, Bentley SJ, D'Andrea AF, Friedrichs CT, Craig NI, Sommerfeld CK (1998) Oceanographic processes and the preservation of sedimentary structure in Eckernförde Bay, Baltic Sea. Continental Shelf Research, 18, $1689-714$.

Orsi TH, Werner F, Milkert D, Anderson AL, Bryant WR (1996) Environmental overview of Eckernförde Bay, northern Germany. Geo Marine Letters, 16(3), 140-7.

Sauter EJ, Laier T, Andersen CE, Dahlgaard H, Schlüter M (2001) Sampling of sub-seafloor aquifers by a temporary well for CFC age dating and natural tracer investigations. Journal of Sea Research, 46, 177-85.

Schardin H (1942) Die Schlierenverfahren und ihre Anwendungen. Ergebnisse der Exakten Naturwissenschaften, 20, 304-405.

Schlüter M, Sauter EJ, Andersen CE, Dahlgaard H, Dando PR (2004) Spatial distribution and budget for submarine groundwater discharge in Eckernförde Bay (Western Baltic Sea). Limnology and Oceanography, 49, 157-67.

Schlüter M (2001) Executive final summary report. Sub-G.A.T.E. Environment and Climate Research Programme Part A, 1-8.

Settles GS (2001) Schlieren and Shadowgraph Techniques: Visualizing Phenomena in Transparent Media. Springer-Verlag, Berlin, Heidelberg, New York.

Sibuet M, Olu K (1998) Biogeography, biodiversity and fluid dependence of deep-sea cold-seep communities at active and passive margins. Deep-Sea Research II, 45, 517-67.

Sonrel L (1868) Le fond de la mer. Librairie De L. Hachette, Paris.

Springer B, Friedrichs M, Graf G, Nittikowski J, Queisser W (1999) A high-precision current measurement system for labor- 
atory flume systems: a case study around a circular cylinder. Marine Ecology Progress Series, 183, 305-10.

Suess E, Linke P (2001) Continuous monitoring of fluid flow at vent sites. Sub-G.A.T.E. Environment and Climate Research Programme Task, 5, 1-6.

Suess E, Carson B, Ritger SD, Moore JC, Jones ML, Kulm LD, Cochrane GR (1985) Biological communities at vent sites along the subduction zone off Oregon. Bulletin of the Biological Society of Washington, 6, 475-84.

Tryon M, Brown K, Dorman L, Sauter A (2001) A new benthicaqueous flux meter for very low to moderate discharge rates. Deep-Sea Research I, 48, 2121-46.

Turekian KK, Tanaka N, Turekian VC, Torgensen T, Deangelo EC (1996) Transfer rates of dissolved tracers through estuaries based on ${ }^{228} \mathrm{Ra}$ : a study of Long Island sound. Continental Shelf Research, 16, 863-73.
Valiela I, Costa J, Foreman K, Teal JM, Howes BL, Aubrey DG (1990) Transport of groundwater-borne nutrients from watersheds and their effects on coastal waters. Biogeochemistry, 10(3), 177-97.

Werner F (1978) Depressions in mud sediments (Eckernfoerde Bay, Baltic Sea), related to sub-bottom and currents. Meyniana, 30, 99-104.

Whiticar MJ (2002) Diagenetic relationships of methanogenesis, nutrients, acoustic turbidity, pockmarks and freshwater seepages in Eckernförde Bay. Marine Geology, 182, 29-53.

Whiticar MJ, Werner F (1981) Pockmarks: submarine vents of natural gas or freshwater seeps? Geo Marine Letters, 1, 193-9.

Zektser IS, Loaiciga HA (1993) Groundwater fluxes in the global hydrologic cycle: past, present and future. Journal of Hydrology, 144(14), 405-27. 
Copyright of Geofluids is the property of Blackwell Publishing Limited and its content may not be copied or emailed to multiple sites or posted to a listserv without the copyright holder's express written permission. However, users may print, download, or email articles for individual use. 